\title{
Identification of Requirements for Distribution Management Systems in the Smart Grid
} Context.

Rezkalla, Michel M.N.; Heussen, Kai; Marinelli, Mattia; Hu, Junjie; Bindner, Henrik W.

Published in:

Proceedings of the 50th International Universities Power Engineering Conference (UPEC 2015)

Link to article, DOI:

10.1109/UPEC.2015.7339932

Publication date:

2015

Document Version

Peer reviewed version

Link back to DTU Orbit

Citation (APA):

Rezkalla, M. M. N., Heussen, K., Marinelli, M., Hu, J., \& Bindner, H. W. (2015). Identification of Requirements for Distribution Management Systems in the Smart Grid Context. In Proceedings of the 50th International Universities Power Engineering Conference (UPEC 2015) (pp. 6). IEEE.

https://doi.org/10.1109/UPEC.2015.7339932

\section{General rights}

Copyright and moral rights for the publications made accessible in the public portal are retained by the authors and/or other copyright owners and it is a condition of accessing publications that users recognise and abide by the legal requirements associated with these rights.

- Users may download and print one copy of any publication from the public portal for the purpose of private study or research.

- You may not further distribute the material or use it for any profit-making activity or commercial gain

- You may freely distribute the URL identifying the publication in the public portal 


\title{
Identification of Requirements for Distribution Management Systems in the Smart Grid Context
}

\author{
Michel Rezkalla, Kai Heussen, Mattia Marinelli, Junjie Hu, Henrik W. Bindner \\ Department of Electrical Engineering (Center for Electric Power and Energy), DTU - Technical University of Denmark \\ Contact Person: Michel Rezkalla, mirez@elektro.dtu.dk
}

\begin{abstract}
The integration of significant volumes of distributed and renewable energy resources directly connected to the distribution network raises new requirement to maintain and operate the power system in secure state. Thus the Distribution Management System (DMS) needs to be updated and integrated with new functionality to provide effective support for the operators. The DMS is a control center solution that provides the needed functionality for the management of medium and low voltage distribution networks. This paper aims to provide an overview of the main functions present in today's DMS platforms and to identify the new requirements to better serve in a smart grid context.
\end{abstract}

Index Terms-active distribution networks, distribution management system, frequency control, smart grid, synthetic inertia.

\section{INTRODUCTION}

To ensure the integration of significant volumes of distributed energy resources (DER) connected to different voltage levels, adequate observability of the system operating state is a requirement for a reliable and secure supply of electricity. From a control system perspective, transmission system operators (TSOs) are able to keep the system stable and balanced because they can observe the transmission grid and control a significant share of the total generation. TSOs control and maintain the system in secure state using energy management system platform (EMS). Energy system management and distribution system management (DMS) have different control objectives. Since the majority of generation resources are connected to the transmission grid, the EMS has an energy focus and provides different functionality compared to the DMS.

The high integration of renewable energy sources (RES) and distributed generation (DG) directly connected to the distribution grid (e.g. wind plants, photovoltaic plants, and active consumers such as electric vehicles) and the deployment of demand response technique transforms the distribution grid from passive grid to active grid. However, the majority of the power flow will be managed by the distribution system operators (DSOs) instead of TSOs.

A great challenge is to control many small and distributed generation units instead of controlling few large generation units. The system could be kept stable and balanced using a centralized control action as it is today (from TSO). In this case we need advanced information communication technology (ICT) infrastructure with huge amount of data to be transmitted to the TSO. Alternative solution is the transition to distributed control action where distributed units could be locally or remotely controlled from the operator. In this case the operator control area is much smaller than TSO's area. Therefor DSO needs to address the challenges since the majority of generation units are connected to the distribution grid which is not sufficiently observed. Implementing a distributed architecture, DSOs will be responsible for local balancing and voltage control replacing some of TSO's role. Therefore, the distribution management system should be updated to better serve the new requirements.

The DMS has a control room focus in assisting the operator to maintain and operate the system in secure state, minimizing losses and optimizing the lines power flow capacity. DMS coordinates real-time functions within the distribution network with the non-real-time (manually operated devices) information needed to properly control and manage the network on a regular basis. The key to a DMS is the organization of the distribution network model database, access to all supporting ICT infrastructure and applications necessary to populate the model and support the other daily operating tasks. DMS functionality can be divided into three categories:

1) System monitoring

2) Decision support

3) Control actions

Moreover, different vendors describe DMS using the combination of two different terms or products, supervisory control and data acquisition (SCADA) and human machine interface (HMI). The major function of SCADA is acquiring data from remote devices such as transmitters and providing an overall control remotely from a SCADA host software platform. The HMI provides a user interface with a graphicsbased visualization to monitor and control the system.

This analysis of DMS functionality is conducted as a part of EU FP7 project ELECTRA IRP[1]. ELECTRA aims to develop new control schemes for the real time operation of the 2030 power system to ensure dynamic balance and stability in a future power system with a high share of decentralized generation. The future power system envisaged in the ELECTRA project will consist in web of cells, defined as a network area with distributed energy resources and loads in a delimited geographical area. Each cell managed by a single operator who takes responsibility of frequency and voltage control. An inter-cell coordination control layer will support system-wide optimized reserves activation if the cell state and system state allows, which imply advanced 
communication infrastructure and new functionality to be integrated into the DMS.

This paper is divided into five sections: in section II we present state of the art of the DMS defining the main functions present in different DMS platforms. In section III we present the future DMS platform requirements to maintain and operate the system in secure state. In section IV conclusion and future work are reported.

\section{STATE OF THE ART}

DMS functionality can be divided into three categories as shown in Fig. 1.

1) System monitoring

2) Control actions

3) Decision support

The system monitoring provides an accurate state of the system using a significant number of real time and near real time information about the current status. The real-time information would include data from remote terminal units (RTU) in substations and feeders. The "near real time" information would include measurement equipment (e.g. distribution substation transformers, load tap changers and distributed generating resources).

The control action is able to control power system apparatus located at distribution substations and field locations. The DMS platform makes available different control actions such as direct control and operator control. The direct control action is realized directly by the DMS without any operator intervention, for example opening a switch breaker to interrupt a fault. The operator control can be divided into two categories, the remote control and the manual control. The remote control is when the operator able to control remotely the apparatus using the SCADA system. The manual control is when the operator needs to call the field crew to open or close a switch which is not remotely controlled [2].

The decision support provides the operator with a set of solutions to enhance the system reliability and efficiency. It provides a decision support solutions as well as appropriate control actions.

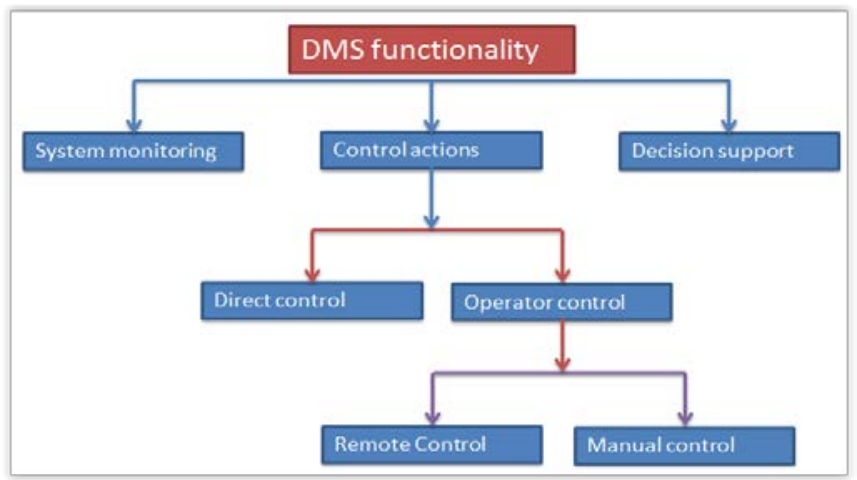

Fig. 1 DMS functionality
The DMS platform is provided by various vendors with different functions. The common and main functions can be summarized as:

1) State estimation

2) Power flow

3) Volt / Var control

4) Fault management and system restoration

5) Short circuit analysis

6) Load management

Following the DMS functionality classification as described in the beginning of this section, the above mentioned functions can be regrouped into the three different categories.

1) System monitoring

- State estimation

- Power flow

2) Control actions

- Volt / Var control

3) Decision support

- Fault management and system restoration

- $\quad$ Short circuit analysis

- Load management

The three categories interact with each other and the operator in order to maintain the system in secure state and optimize the system operation. The different functions are linked to each other even if they belong to a different group. For example, the state estimation belongs to the system monitoring category but at the same time the state estimation evaluation is used in the Volt / Var tool. In Fig. 2 we represented the interaction between the three functionality categories.

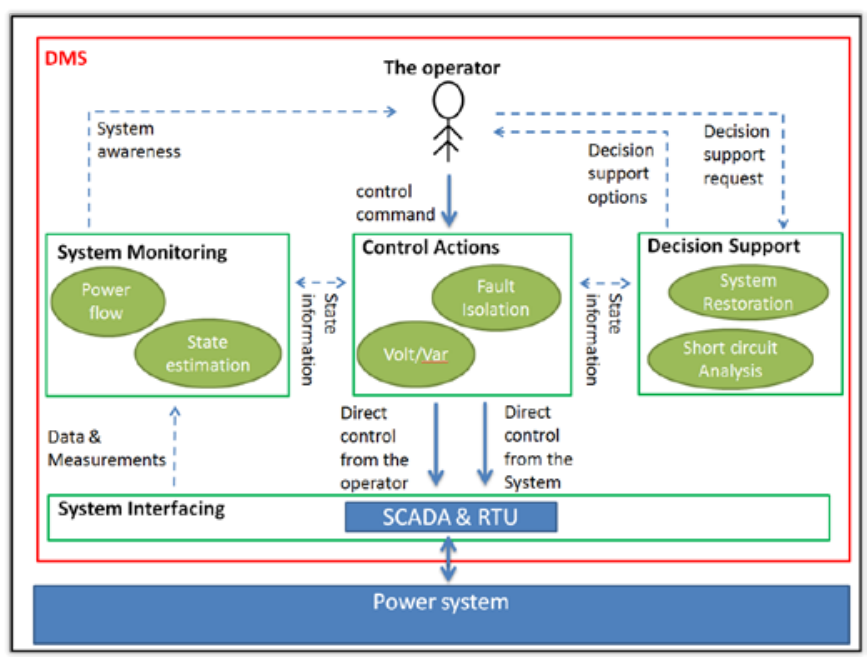

Fig. 2 Interaction between the different DMS functionality categories; solid arrow means control actions, dotted arrow means data and measurements

\section{A. State estimation}

The state estimation has a fundamental role in monitoring and controlling the system and is a key functionality in the EMS, being responsible for estimating the state of the power system. As the distribution grid is becoming active due 
mainly to the integration of distributed renewable generators directly connected to the low and medium voltage grid, the state estimation started to be a key function in the DMS. The state estimation recreates values for different distribution system variables using the available data present in the SCADA system[3].

\section{B. Power flow}

The power flow function is a numerical analysis of the power flow in an interconnected system. These calculations are initiated on periodic basis or in case of any significant change in the network. The operator can also initiate the calculation if needed. This tool use different visualization technique, for example a single line diagram to provide the operator with the electrical conditions as well as the power distribution on the different lines, assisting the operator to understand the system state and abnormal conditions e.g. overload in line sections [2].

\section{Volt / Var control}

Volt / Var control determines the best control action to maintain the voltage profile within a desired range and minimizing system losses controlling the reactive power flow in the distribution system [4]. This function provides the operator with the best actions and recommendations to maintain the high quality voltage profile minimizing the losses and the reactive power demands. During this operation different resources can be used such as Tap Changer, Facts devices and capacitor banks.

\section{Fault management and system restoration}

This is a restoration functionality which improves reliability and power quality reducing the number of customer affected by the fault and the outage time duration. The tool detects and isolates the faulted section, then restores the service using a new configuration of the network. In the following paragraph is presented a use case with three loads and a fault between Load 1 and Load 2 as shown in Fig. 3.

The logical intelligent devices identify the fault location and decide the best action to isolate the fault and restore the service to the unaffected customers. The programmed logic based on the RTU will isolate the fault by opening Breaker 2 to interrupt the power flow to Load 2 and Load 3, as shown in Fig. 4. Afterwards the normally open Breaker 4 will be closed to restore the service to Load 3 minimizing the number of customers affected by the fault, as it is shown in Fig. 5[5].

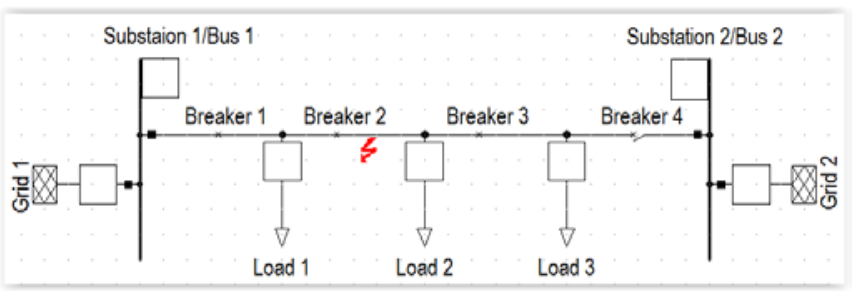

Fig. 3 Load 1, Load 2 and Load 3 are connected to substation 1

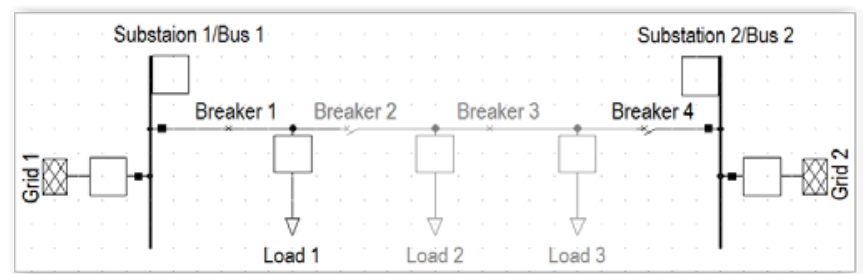

Fig. 4 The fault management tool will isolate the fault opening Breaker 2 and isolating Load 2 and Load 3

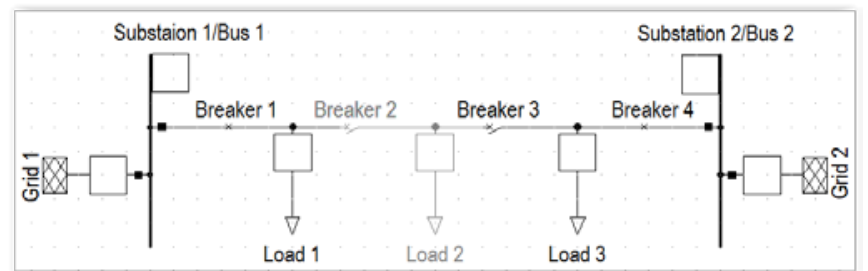

Fig. 5 The fault management tool will restore the service to Load 3opening Breaker 3 and closing Breaker 4

\section{E. Short circuit analysis}

Short circuit analysis allows the operator to calculate the current after an estimated fault condition in the system, providing him the estimated value to be compared with the switchgear breaking capabilities and limits. This function assists the operator during the network reconfiguration.

\section{F. Load management}

Since base load peak load ratio can be very high in distribution network which cause a stress on both lines and feeders, the load management must reconfigure the network to handle this situation achieving high efficiency in the system operation. Fig. 6 shows a normal configuration of the network where all the three loads are connected to Grid A. Assuming an overloading on the connection line between Grid A and the others loads, the DMS will propose a different switching configuration to optimize the grid operation as shown in Fig. 7.

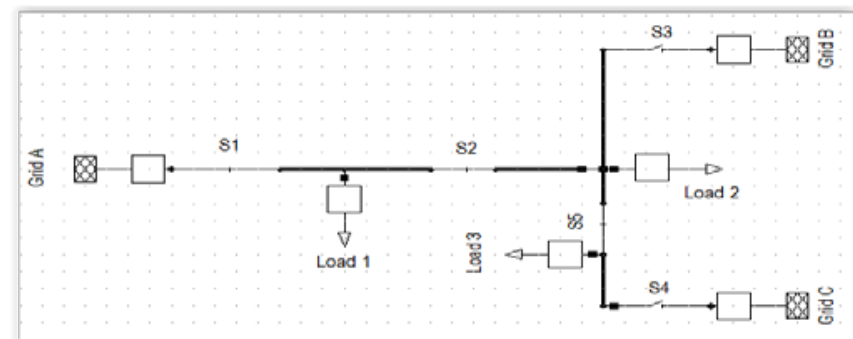

Fig. 6 Load 1, Load 2. and Load 3 are connected to Grid A

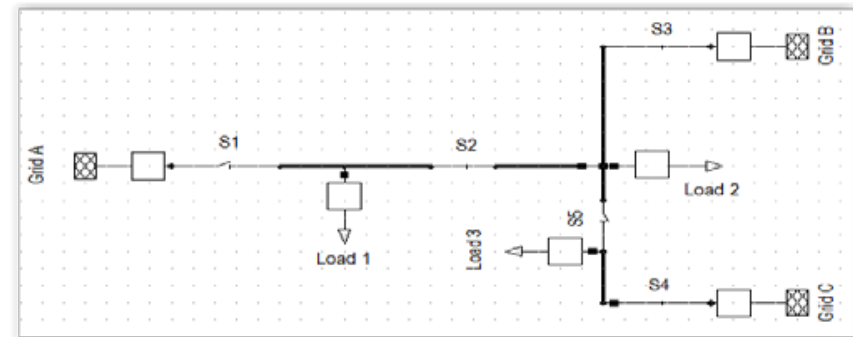

Fig. 7 Load 1and Load 2. are connected to Grid B while Load 3 is connected to Grid C 


\section{FUTURE REQUIREMENTS}

Based on different EU projects, it is expected that by 2030 between $52 \%$ and $89 \%$ of electricity production will be generated by renewable energy resources mainly connected to the distribution grid [6], [7]. The integration of distributed generators and renewable resources into the grid raises new needs to control and maintain the system in secure state. To provide solutions for the different challenges that DSOs are facing today (addressed in the first section), advanced DMS applications are needed. The authors foresee new needs to operate and control the system and consequently new functions to be integrated into the DMS. Fig. 8 presents an overview of the DMS platform new requirements.

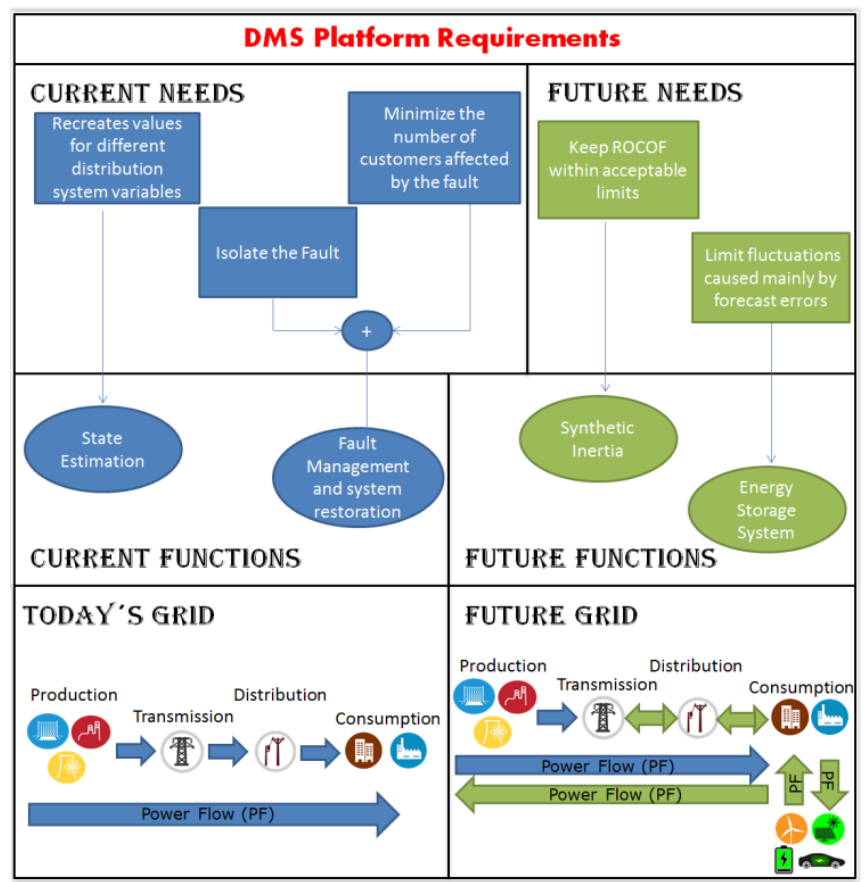

Fig. 8 DMS presentation with the actual and future needs

On the left side of Fig. 8 we have the current functions related to the current needs while on the right side we have new needs and the related functions. This section defines different uses cases taking into account the smart grid context and the ELECTRA project.

\section{A. Load Estimation}

Since the distribution system was mainly passive there was no need to measure and monitor the different bus loads. Nowadays with the integration of active consumers such as electric vehicles (EV) and residential photovoltaic (PV) systems, the load estimation and forecasting become complicate but more fundamental for operational planning and real time control of the grid. One of the solutions to overcome the lack of measurement in the distribution grid is the use of intelligent devices (IED) that can be programmed to perform certain automated tasks. IED can replace the traditional electromechanical relays providing additional functionality such as measurement of instantaneous volts, amp and power improving the load estimation reliability [5]. One of the challenges is to collect and communicate in real time those values to the DMS database updating the load estimation algorithm. Thus advanced communication technologies and new measurement devices need to be integrated between the DMS and the field to support the load estimation function. For example, different RTU devices are integrated with Modbus/TCP/IP/ fiber optic ports to improve the communication between field devices and RTU.

\section{B. Load Geographical Information System (GIS)}

Following the distributed control architecture and the transition of the power production from few large generation units to many small generation units, raise new needs for the system operator. The system operator could be a cell operator referred to the ELECTRA project or the DSO referred to the current architecture. The system operator need to control voltage deviation and power flow imbalances using resources located as close as possible to the occurring problem to minimize the reactive power flow distance and consequently the losses. Therefore the operator needs to be aware of the resources position. The geographical Information System should be integrated into the network model providing the operator with a geographical representation of the network, as it is shown in Fig. 9.

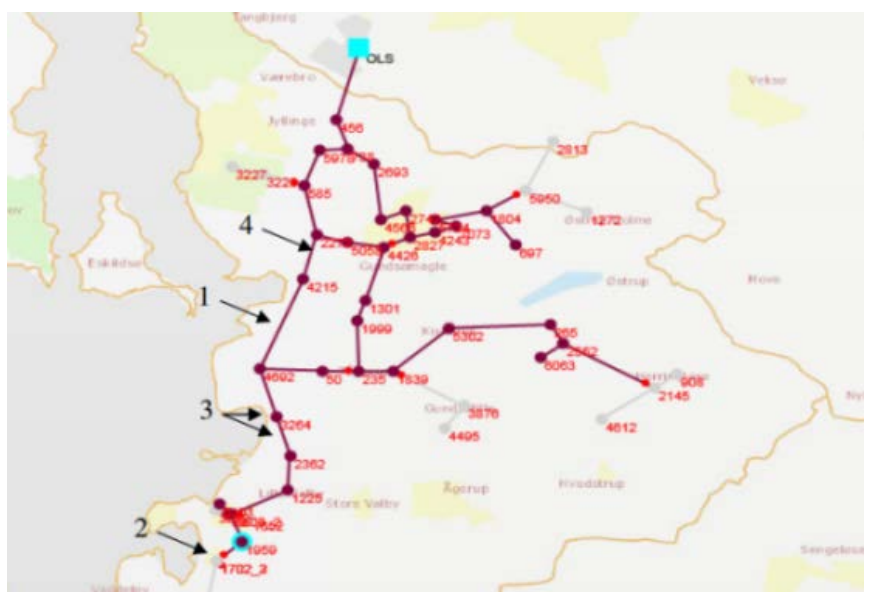

Fig. 9 A portion of the LV network operated by DONG-Denmark [8]

Different Distribution System Operators (DSO) started to upgrade the DMS to achieve better real time visualization. For example, Dong Energy in collaboration with Schneider Electric started to integrate a new DMS system. The new DMS can represent the network as a schematic representation as well as a geographical representation. Thus the operator will have a better overview of the system and will be also able to guide more efficiently the field crew [8].

\section{Synthetic inertia}

The system inertia in the power system smooths both small and large frequency variations after a disturbance, keeping the rate of change of the frequency (ROCOF) within acceptable limits. In today's power system the ROCOF is limited mainly by the kinetic energy in the rotating generators. The variation in the rotor speed implies a 
variation in the kinetic energy transformed into electric power to be changed with the grid. This dynamic is described by the equation of motion[9]:

$$
T_{m}-T_{e}=J \frac{d \omega_{m}}{d t}
$$

The rotational rate of change $\frac{\mathrm{d} \omega_{\mathrm{m}}}{\mathrm{dt}}$ of the machine is proportional to the difference between the mechanical input torque to the machine $\mathrm{T}_{\mathrm{m}}$ and the electrical load on the machine $\mathrm{T}_{\mathrm{e}}$. The rotational rate of change is scaled by the moment of inertia J.

In the future power system we are facing a new challenge due to the integration of static generators (converters) replacing the rotating machines. Thus the direct coupled inertia provided by direct-coupled machines decreases [10]. For example PV systems and wind turbines connected to the grid with full converter. A solution could be the synthetic inertia response which is a facility able to replicate the inertia response of rotating machines. For example some wind turbine manufactures such as General Electric and ENERCON have started to integrate controllers on modern wind turbine generators in order to provide synthetic inertia [11], [12]. Synthetic inertia can also be provided using energy storage connected to converter coupled generators.

As envisioned in the ELECTRA architecture, also the inertia needs to be properly handled by the DMS [10] Therefore the DMS should include a new function to provide the operator in real time the total available amount of inertia response within the cell, the available amount that could be delivered to neighbor cells and the available amount that could be received from neighbor cells.

\section{Energy storage monitoring}

According to the recommendations for the European Energy Storage Technology Development Roadmap [13] , electrical storage prices are projected to drop. Therefore storage will be a cost effective solution for offering ancillary service. Electrical storage could deal with the fluctuations caused mainly by forecast errors and renewable resources intermittency. The storage technology started to be tested in different EU projects such as Grid4EU. The DMS should provide the operator with the battery schedules, location and the related energy prices in such a way to enable the operator to use energy storage systems available within the cell as well as energy storage systems from neighbor cells.

\section{E. Vehicles to grid}

Electric Vehicles have become quite popular in some countries due to climate change concerns and different advantages such as cheaper fuel and more silent operation. For example, in Norway are present more than 13.000 EVs [14]. Through smart grid, EVs can offer a unique benefit called vehicle to grid (V2G) technology. Electric vehicles with V2G capabilities can be considered as controllable loads responding to frequency fluctuations [15]. The operator needs to take advantage of the connected EVs to the grid and the relative percentage of power that could participate in the primary frequency control [16], [17]. Therefore the DMS needs to integrate new algorithms to allow the participation of EVs in the primary frequency control.

\section{F. Scaling DMS for supervisory control}

The increasing penetration of distributed generation units into distribution grids implies new requirement to control the system from TSOs and DSOs level. The deployment of DER units increases the responsibility of DSOs. Increasingly TSO and DSO are required to communicate to maintain the system in secure state. We observe a development to more active distribution grids, which we can classify into four stages:

1) Increased observability

2) Active network management

3) Transfer of (control) responsibility to DSOs

4) Self-responsible distribution system operation

Stage 1: In the near future DSOs need to increase the distribution grid observability due to the high integration of DER units and renewable resources which are weather dependent[18]. For example in Germany PV are monitored and support frequency by local control. According to the German VDE AR-N 4105 guidelines for the low and medium voltage grid, frequencies over $50.2 \mathrm{~Hz}$ lead to smooth power reduction of $\mathrm{PV}$ systems according to a predefined characteristic curve [19].

Stage 2: Active power management of DER units is becoming increasingly important for solving congestions in both transmission and distribution grid. For example, German feed-in tariff law has required owners of PV systems with active power less than $30 \mathrm{kWp}$ to either limit the reactive power output to $70 \%$ of the installed capacity or install a remote control interface to receive temporal power reduction signals from the DSO, if necessary. Units with more than 30 kWp must be controllable remotely[19].

Stage 3: We foresee that DSO in the feature will support more actively TSO in controlling the system, transferring some of TSO's responsibility to DSO. For example, reactive power management could be handled by the DSO. In line with that, Swissgrid, the Swiss TSO, developed a concept for the coordinated voltage control of the 220/380 kV transmission system that enables, along with transmission connected power plants, the active participation of underlying distribution grids[20].

Stage 4: Following the ELECTRA web of cells concept, the DSO will be completely responsible of the voltage and frequency control of his own cell. For example, active and reactive power management.

It can be observed that stages 1 and 2 already led to more TSO-DSO interaction. For example TSOs having access to online measurement of DER units connected to the MV grid which belong to the DSO's grid; and able to curtail those units in case of necessity by an official communication to the DSO (e.g. phone call).

To analyze how the supervisory control supported by the DMS, we distinguish three types of control approaches: local, centralized and distributed control. 
The local control of Stage 1 does not require communication with the DMS since the DER units react to specific situations according to predefined parameters. For example, disconnection of PV inverters at over frequency values predefined from DSOs. Here, no supervisory control, but only increased observability is needed.

The central control technique is a communication based approach where the distribution system operator able to control remotely and individually each DER unit. For example, remotely curtail the active power of a wind plant to resolve congestion issues [19]. Supervisory control for centralized control systems is straightforward, due to a clear command hierarchy.

The distributed control techniques are communication based control strategy. For example, different DER units clustered into different cells with integrated autonomous control to support grid stability and optimize the economic efficiency. Practical application is implemented in the PV systems. Different PV units are clustered together and controlled from a micro DMS in the substation and monitored by the DSO. Supervising such is more complex, as it requires observation of both the internal state and goals of the distributed controller as well as the of the detailed network state.

In a realistic distribution grid, the need for supervision and control will depend on the actually deployed resources. Therefore a flexible, layered or modular DMS architecture will be required.

\section{CONCLUSION AND FUTURE WORK}

The introduction of distributed energy resources into the power system requires new control schemes and coordination between different actors. This paper presented the state of the art of the distribution management system related to the current needs and detailing some of the functions present in different platform. This paper also presented the new requirement of the system operator to maintain and operate the system in secure state and identify the related new function to be integrated in the DMS. Supervisory control of the DMS, new roles of DSOs and the interaction between TSOs and DSOs have been presented.

Future work will deal with the definition of analytics for power systems supervisory controls and with the investigation of new control architecture and DMS system architecture.

\section{ACKNOWLEDGEMENTS}

Michel Rezkalla is Ph.D. student at the Technical University of Denmark (DTU) and is supported by the EU FP7 project ELECTRA (grant: 609687) and the Danish Research Project "ELECTRA Top-up” (grant: 3594756936313). More information at www.electrairp.eu

\section{REFERENCES}

[1] L. Martini, A. Morch, L. Radaelli, C. Caerts, C. Tornelli, S. Hänninen, and H. Brunner, "Electra IRP approch to voltage and frequency control for future power systems with high DER penetration,” in 23rd International Conference on Electricity Distribution CIRED, 2015, no. June, pp. 1-5.

[2] E. Vaahedi, Practical Power System Operation, 1st ed. John Wiley \& Sons, 2014.

[3] A. Jain and N. R. Shivakumar, "Power system tracking and dynamic state estimation," Conf. Expo. 2009. PSCE '09. IEEE/PES, pp.1,8, 1518 March 2009.

[4] S. Rahimi, M. Marinelli, and F. Silvestro, "Evaluation of requirements for Volt/Var control and optimization function in distribution management systems,” 2012 IEEE Int. Energy Conf. Exhib. ENERGYCON 2012, pp. 331-336, 2012.

[5] K. M. Muttaqi, J. Aghaei, V. Ganapathy, and A. E. Nezhad, “Technical challenges for electric power industries with implementation of distribution system automation in smart grids,” Renew. Sustain. Energy Rev., vol. 46, pp. 129-142, Jun. 2015.

[6] D. Six, A. Ramos, and E. R. Puente, "D1.2: Evaluation of current market architectures and regulatory frameworks and the role of DSOs," 2014.

[7] "Status review on the transposition of unbundling requirements for DSOs and closed distribution system operators,” 2013.

[8] M. Møller, R. Larsen, I. Stefani, and D. Djapic, "On the Implementation of an Advanced Distribution Management System,” in NORDAC 2014, 2014.

[9] P. Kundur, Power System Stability and Control. McGraw-Hill, 1994.

[10] C. Caerts, R. D’hulst, S. De Breucker, E. Rikos, D. Kolodziej, J. M. Fernandez, E. Rodríguez, and K. Heussen, "ELECTRA Deliverable D3.1 Specification of Smart Grids high level functional architecture for frequency and voltage control,” vol. 3. http://www.electrairp.eu, pp. 1100, 2014.

[11] F. . Gonzalez-Longatt, "Effects of the Synthetic Inertia from Wind Power on the Total System Inertia: Simulation Study," in Environment Friendly Energies and Applications (EFEA), 2012 2nd International Symposium on, pp. 389 - 395.

[12] E. Muljadi, V. Gevorgian, and M. Singh, "Understanding Inertial and Frequency Response of Wind Power Plants,” in IEEE Symposium on Power Electronics and Machines in Wind Applications, 2012, no. July.

[13] O. Teller, J.-P. Nicolai, M. Lafoz, D. Laing, R. Tamme, A. Schroeder Pederson, M. Andersson, C. Folke, C. Bourdil, M. Conte, G. Gigliucci, I. Fastelli, M. Vona, M. Rey Porto, T. Hackensellner, R. Knapp, H. J. Seifert, M. Noe, M. Sander, J. Lugaro, M. Lippert, P. Hall, R. Saliger, A. Harby, M. Pihlatie, N. Omar, J.-M. Durand, and P. Clerens, "Joint EASE / EERA recommendations for a European Energy Storage Technology Development Roadmap towards 2030,” 2013.

[14] T. E. Nørbech, "Incentives and infrastructure - crucial elements in the build-up of Norway’s EV fleet,” in EVS 27 Barcelona, Spain, 2013, pp. $17-20$.

[15] A. Zarogiannis, M. Marinelli, C. Træholt, K. Knezovi, and P. B. Andersen, "A Dynamic Behaviour Analysis on the Frequency Control Capability of Electric Vehicles," in Power Engineering Conference (UPEC), 2014, pp. 1-6.

[16] S. Martinenas, M. Marinelli, P. B. Andersen, and C. Træholt, "Implementation and demonstration of grid frequency support by V2G enabled electric vehicle," in Proceedings of the 49th International Universities Power Engineering Conference (UPEC) IEEE, 2014, pp. $1-6$.

[17] J. R. Pillai, B. Bak-Jensen, and P. Thogersen, "Electric vehicles to support large wind power penetration in future Danish power systems," IEEE Veh. Power Propuls. Conf. VPPC, no. 09-12 Oct, pp. 14751479, 2012.

[18] C. Bovo, V. Ilea, M. Subasic, F. Zanellini, C. Arigoni, and R. Bonera, "Improvement of Observability in Poorly Measured Distribution Networks," in 18th Power Systems Computation Conference, 2014, pp. $1-7$.

[19] J. von Appen, M. Braun, T. Stetz, K. Diwold, and D. Geibel, "The Challenge of High PV Penetration in the German Electric Grid," IEEE Power Energy Mag., no. February, pp. 55-64, 2013.

[20] M. Zerva and M. Geidl, "Contribution of active distribution grids to the coordinated voltage control of the Swiss transmission system," in 18th Power Systems Computation Conference, 2014, pp. 1-8. 